\title{
Analysis of Flexural Strength Test Results of Coconut Fiber and Corn Husk Composite for Hanging Rack
}

\author{
Syamsul Hadi ${ }^{1, a}$ and Bangkit Agung Sudrajat ${ }^{2, b}$ \\ 1,2 Mechanical Engineering Department, State Polytechnic of Malang, Jalan Soekarno Hatta No.9, Malang 65141, Indonesia \\ asyamsul.hadi@polinema.ac.id \\ babangkit02@gmail.com
}

\begin{abstract}
The wood demand for construction, buildings and furniture is always increasing, while the availability of wood continues to decline with the growth of the wood industry. The purpose of this study was to determine the best flexural strength of the variation of composite board resin material with filler fibers of Coconut Fiber and Corn Husk (CFCH) with comparative specimens of particle boards and Sengon wood. Preparation of composite specimens from Yucalac 157 BQTN-EX polyester resin type added by CFCH fillers with different weight fractions, composite specimens were made accordance with ASTM-D 7264 standard size. Analysis of test data using OnewayAnova approach. The best percentage results on the composition of the weight of the hanging rackcomposite with the ratio of filler CFCH was $4.5 \%$ : $4.5 \%$ (1: 1) with $91 \%$ hardener resin, and the weight fractions of CFCH was affected to the flexural strengthcomposite, because $F_{\text {calculated }}>F_{\text {table }}(15.05>$ 5.14).
\end{abstract}

Keywords--Coconut Fiber, Corn Husk, Flexural Test, Particle Board, Sengon Wood.

\section{Introduction}

Based on Indonesian Forestry Statistics data, the production and distribution of logs by type $\left(\mathrm{m}^{3}\right)$ continued to increase for $\log$ in 2014 which recorded $38,605,470.39 \mathrm{~m}^{3}$, and in 2015 recorded $43,866,227.17$ $\mathrm{m}^{3}$ increased by $13 \%$ [1]. The demand for wood for construction, buildings and furniture is always increasing, while the availability of wood continues to decline followed by the growth of the wood industry which is increasing. These conditions cause the wood industry to have difficulty in obtaining raw materials to support its production process. To overcome these problems an alternative of wood demand is composite boards.

Composite materials are known to be lightweight, strong, not affected by corrosion, and able to compete with metals, by not losing their characteristics and mechanical strength, especially coconut fiber and corn husk
Coconut fiber is one component of coconuts which processed and decomposed can become products needed for the domestic market and even become high export value products. With this article, it is expected that information about the benefits and materials generated from coconut fiber waste can be more widespread, so that both the government, small industry, designers and the wider community can apply and choose coconut fiber materials that are environmentally friendly and renewable (sustainable) to be part from sustainable design development programs, green design, social entrepreneurship, and other related programs [2].

The mechanical strength of corn husk fiber filler can qualify as a composite fiber board in accordance with JIS A5905-2003 [3].

Single fiber composite kenaf, bamboo, and coconut fiber reinforcement showed lower tensile strength values compared to combine composite [4].

Soaking coconut fiber into $5 \% \mathrm{NaOH}$ solution for 2 hours at an optimal tensile strength value with a value of $21.075 \mathrm{MPa}$ [5]. The coconut fibers have been treated by alkaline to increase thermal stability [6].

Filler without treatment and with alkali treatment as well as the percentage of volume fraction and the variation in the length of the fiber in a straight fiber orientation have an influence on the composition of the mechanical properties of the composite [7]. Hemp fiberreinforced composites with $5 \% \mathrm{NaOH}$ treatment for 2 hours have greatest tensile strength [8].

Injection method is a method of making composites by flowing hardener resin using injection into a closed mold which is given 2 holes as the entrance and exit of hardener resin [9] as shown in Figure 1. The mold assembly are consist of top mold, middle mold, and bottom mold. 


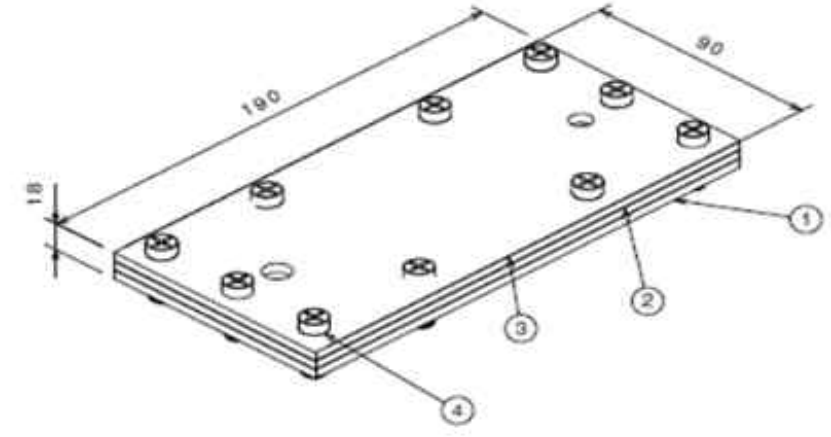

\begin{tabular}{|c|c|l|c|c|}
\hline 4 & - & Bolt & Steel & M8 \\
\hline 3 & - & Top Mold & Acrylic & $190 \times 90 \times 4$ \\
\hline 2 & - & Middle Mold & Acrylic & $190 \times 90 \times 10$ \\
\hline 1 & - & Bottom Mold & Acrylic & $190 \times 90 \times 4$ \\
\hline Position & No. Identification & Part Name & Materials & Dimensions (mm) \\
\hline
\end{tabular}

Figure 1. Mold for Injecting Composite Specimen [7]

From previous studies, it can be concluded that hybrid composites are better than composites with a single filler. Corn husk fillers have a significant effect on Yucalac 157 BQTN-EX resin combined with coconut fiber filler as a continuation of the study [1].

\section{A. Research variable}

\section{Research Methods}

The research variables consist of:

1. Independent Variable

The independent variable in the study was the weight composition ofCFCH.

2. Dependent Variable

The dependent variable in this study is the result of testing the flexural strength of composites.

3. Control Variables

The control variable of research is the weight composition of the resin.

\section{B. Hypothesis}

The research hypothesis consist of:

1. Hypothesis $\mathrm{Nul}\left(\mathrm{H}_{0}\right)$

The following hypothesis is as follows:

There is no significant effect between the $\mathrm{CFCH}$ weight percentages on the flexural strength of composite boards.

2. Alternative Hypothesis $\left(\mathrm{H}_{1}\right)$

The alternative hypothesis is as follows:

There is a significant influence between the weight percentage of $\mathrm{CFCH}$ on the flexural strength of composite boards.
The research flowchart is shown in Figure 2.

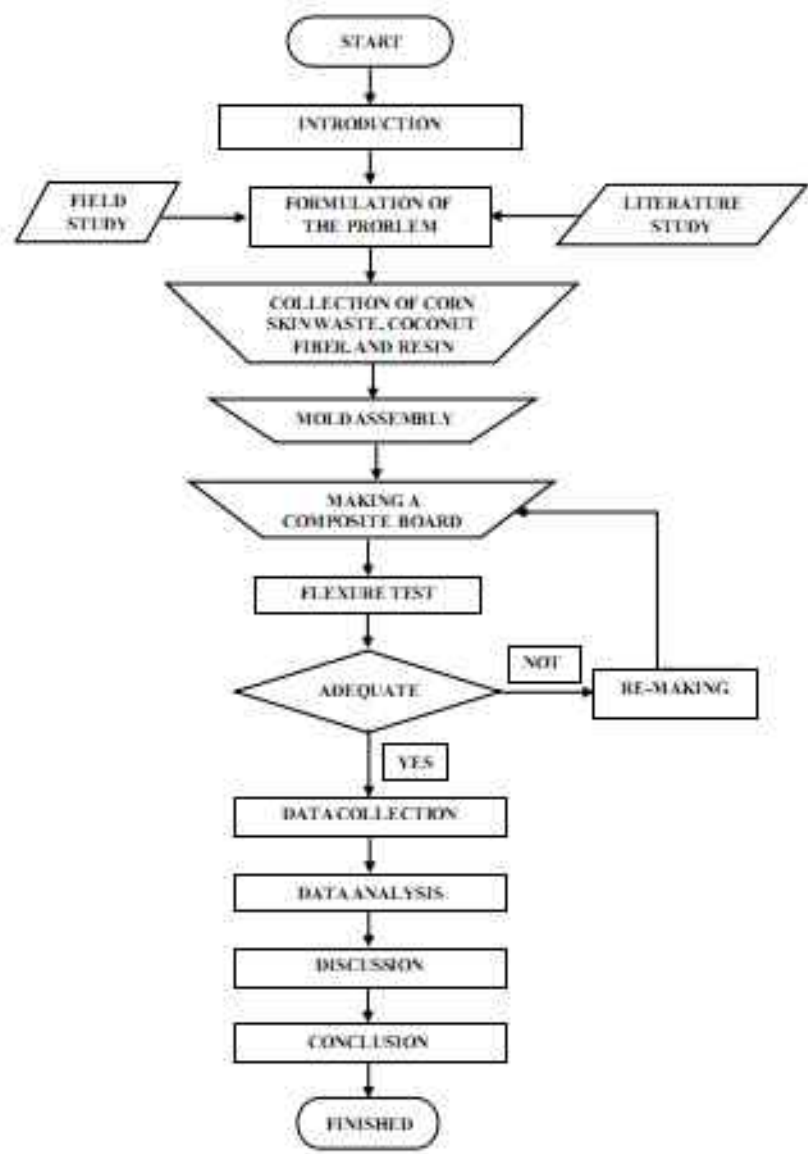

Figure 2. Research Flowchart

\section{Mold Preparation}

Molds for specimen are made of acrylic materialswith the dimensions of $190 \mathrm{~mm} \times 90 \mathrm{~mm} \times$ 18 mmby 3 parts, namely the basemold (a), middle mold (b) and top mold (c)is shown in Figure 3.

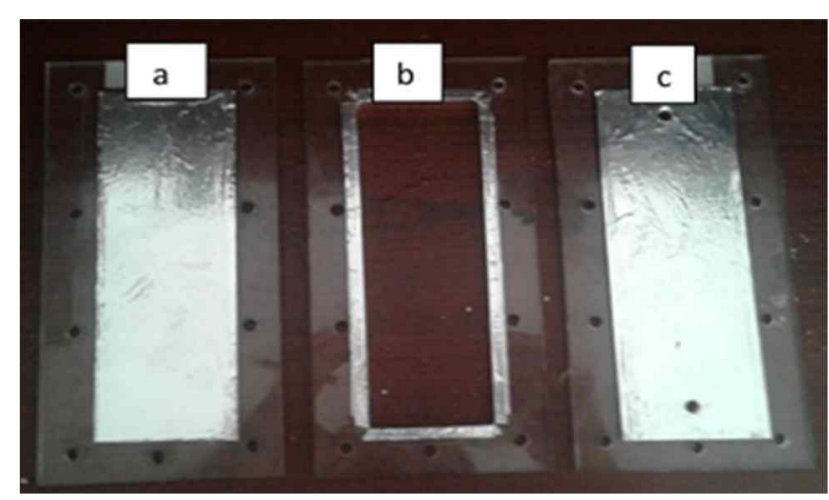

Figure 3. Molds for making Specimens [9]

From Figure 3 it is known that the mold consists of three parts namely: 
1) In the letter a is the bottom of the mold that functions as a fiber support,

2) In the letter $b$ is the middle of the mold that functions as a regulator of the dimensions of the specimen that is $150 \mathrm{~mm} \times 40 \mathrm{~mm} \times 10 \mathrm{~mm}$,

3) In the letter $\mathrm{c}$ is the top of the mold that functions as a cover mold and as a channel for charging a hardener resin and hardener resin discharge.

\section{Specimens Preparation}

Composite specimens are made from coconut fiber and corn husk fibers that have been cleaned by plain water, soaked using alkali of $5 \% \mathrm{NaOH}$ for \pm 2 hours, then rinsed and dried in the hot sun to dryat 11.30 a.m. to 00.30 p.m. Coconut fiber and corn husk fibers that have been cleaned and cut $150 \mathrm{~mm}$ long and then placed in a drinking straw to maintain their straightness before being put into the mold.Injection specimen preparation using Yucalac 157 BQTN-EX polyester resin according to standard of ASTM-D 7264 [10] is shown in Figure 4.

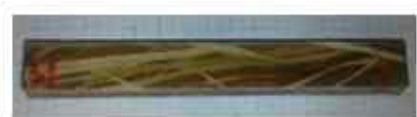

(a)

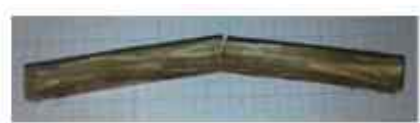

(b)

Figure 4. Test specimens: (a) Before, (b) After

\section{E. Flexural Test}

Flexture test is applied to materials that accept bending loads such as metal springs, floor tiles, stone slabs, wooden boards/beams, plastic rods/spikes/pipes, and concrete slabs [11]. Flexural strength is generally tested by the three-point bending method is shown in Figure 5.

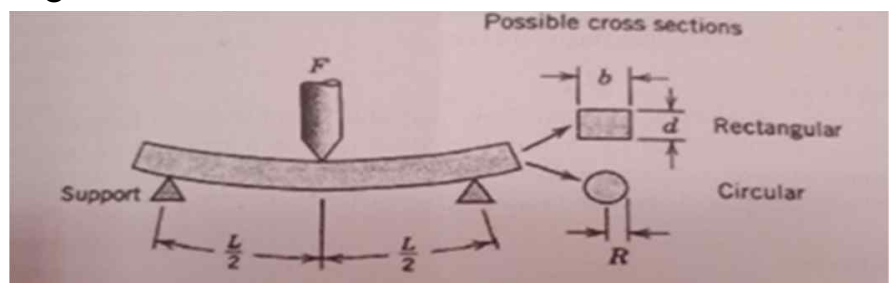

Figure 5. Test the Flexural Strength of the Three-Points Bending Method [12]

Universal Testing Machine Tarno Grockiusually also known as Universal Testing Machine which is a machine that can be used for tensile tests, compression test, flexural tests, and shear tests is shown in Figure 6.

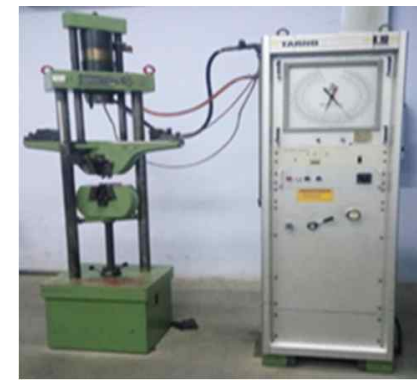

(a)

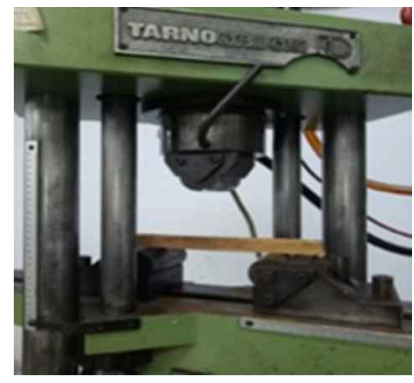

(b)
Figure 6. Tarno Grocki's Universal Testing Machine (a) Bending Test Machines \& Control Panels, and (b) Setting of Bending Test Specimens

This machine provides deflection information and flexural forces on the material from which the flexural strength can be calculated, so that it can be plotted as a graph of stress-deflection.

\section{Results and Discussion}

Results and discussion of the CFCH1 Composite flexural strength analysis for hanging rack:

\section{A. Calculation Results}

Table 1 shows the results of the One-way Analisys of variance (Anova) calculation using Microsoft Excel 2003.

Table 1. One-Way Anova Calculation Results

\begin{tabular}{|c|c|c|c|c|c|c|}
\hline Source of Variation & SS & df & MS & F & P-value & Fcrit \\
\hline Between Groups & 117.44 & 2 & 58.72 & 14.85 & 0.005 & 5.14 \\
\hline Within Groups & 23.73 & 6 & 3.95 & & & \\
\hline Total & 141.17 & 8 & & & & \\
\hline
\end{tabular}

The purpose of $F_{\text {crit }}$ is Percentage Point according to the Distribution of F [13], while F is calculated as $F_{\text {table. }}$.

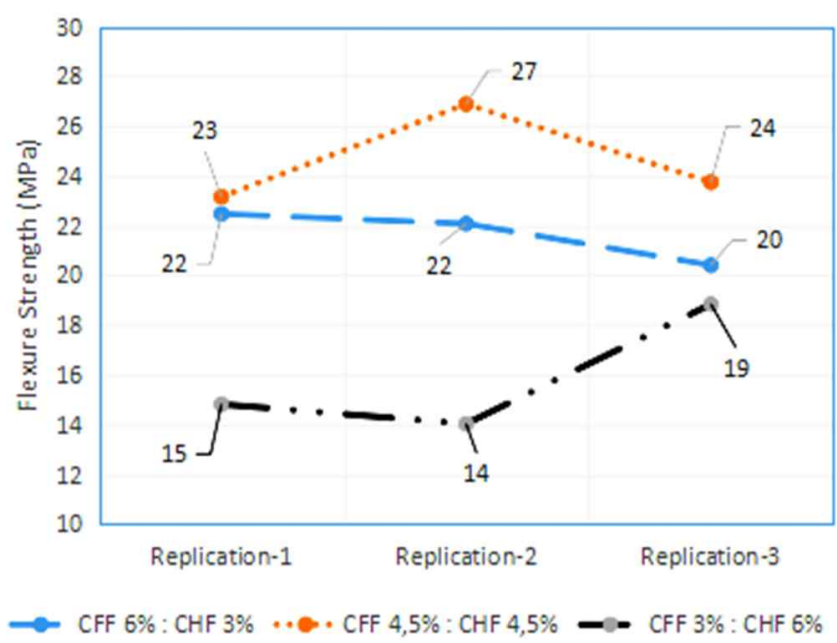

Figure 7. The Lowest Chart of Each Replication 
Figure 7 shows the lowest yield strength $\left(\sigma_{\mathrm{y}}\right)$ of each specimen compared to the comparison specimen, namely particle board and Sengon wood is shown in Tabel 2 and Figure 8 . The number of specimens prepared was 6 types with repetitions of $3 \mathrm{x}$ each, therefore 18 specimens were needed for the flexural test whose average results are shown in Table 2.

Table 2. Flexure Strength for some Material Type

\begin{tabular}{c|l|c}
\hline No. & Material Type & $\boldsymbol{\sigma y}$ (MPa) \\
\hline 1 & CFCH1 & 23 \\
\hline 2 & CFF & 11 \\
\hline 3 & CHF & 10 \\
\hline 4 & Sengon Wood & 32 \\
\hline 5 & Particle Board & 12 \\
\hline 6 & CFCH2 & 33 \\
\hline
\end{tabular}

$\mathrm{CFCH} 2$ is an improvement in the flexural strength of $\mathrm{CFCH} 1$ by following the filling of coconut fiber and corn husk in the composition of CFCH1 which is 1 part coconut fiber and 1 part corn husk until it contains a maximum (about 2 times) into a specimen mold for the composite combination of these fibers.

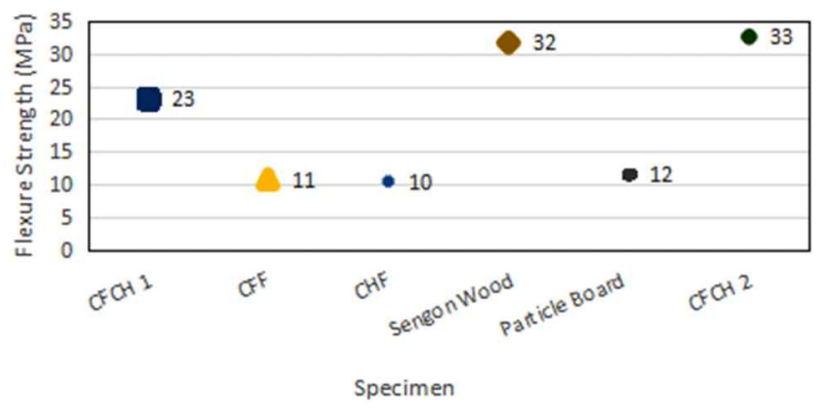

Figure 8. Flexure Strength Comparison Chart

\section{B. Discussion}

Discussion of research results:

1. In Table 1, because $F_{\text {calculated }}$ from the composite CFCH1 $>\mathrm{F}_{\text {table }}(14.85>5.14)$, then hypothesis 1 is accepted, that means there is an influence of the weight percentage $\mathrm{CFCH} 1$ on the yield strength of the hanging rack composite,

2. Figure 7 shows that the yield strength of the composite board flexural test with $3 \%$ weight of coconut fiber and $6 \%$ corn husk fiber has the lowest yield strength of $14 \mathrm{MPa}$, while for the highest $\sigma_{\mathrm{y}}$ on CFCH1 with weight percentage of $4.5 \%$ coconut fiber and $4.5 \%$ corn husk fiber worth $27 \mathrm{MPa}$. The addition of coconut fiber in the composite has an optimum value for a particular composition, so the addition is limited to a certain amount as stated that the flexural strength of coconut fiber-epoxy composite were decreased when the filler of coconut fiber were increased [14]. The increasing number of corn husk composite fibers results in decreased composite flexural strength as stated that the flexural strength of corn husk fiber composite is decreased with increasing corn husk fiber filler and increased if mesh size is smaller [15]. So the composition of coconut fiber and corn husk fiber should be in accordance with the optimum research done in this study, with a ratio of $1: 1$.

3. The Figure 8 shows that the lowest $\sigma_{\mathrm{y}}$ of the $\mathrm{CFCH} 2$ composite specimen has a value of $33 \mathrm{MPa}$, while the lowest $\sigma_{\mathrm{y}}$ of Sengon wood has a value of $32 \mathrm{MPa}$, that means the composite board can be used as a substitute for Sengon wood.Comparisons cannot be made with similar research results, because no one has used them with the same fibers and matrix compositions, but comparisons are made with construction materials that can be replaced by composites with coconut fibers combined with corn husks, namely particle board and Sengon wood.

\section{Conclusion}

1. The best percentage results of the composition of the weight of the hanging rack composite $\mathrm{CFCH}$ is at the ratio of $4.5 \%$ : $4.5 \%$ (1:1) $\mathrm{CFCH}$ filler with $91 \%$ hardener resin,

2. The weight composition of $\mathrm{CFCH} 1$ has a significant effect on the flexural strength of the composite, because $\mathrm{F}_{\text {calculated }}>\mathrm{F}_{\text {table }}(14.85>5.14)$, and

3. For further work, it is better to research by adding the amount of filler weight to the composite, so that the flexural strengthvalue of the composite can exceed the flexural strength of Sengon wood and may different types of wood.

\section{Acknowledgement}

Gratitude to the Head of Material Testing Laboratory, Department of Mechanical Engineering, State Polytechnic of Malang for assistance in using Universal Testing Machine in the process of flexural research of coconut fiber and corn husk composite materials. 


\section{References}

[1] Anonymous. Statistics on Forestry Production, Statistics Indonesia. Jakarta. 2016.

[2] Indahyani, T., Utilization of Coconut Fiber Waste, Binus, 1-3 \& 8. 2011.

[3] Silalahi, P.S., Manufacture and Characterization of Polyester Corn Husk Fiber Composites by The Chopped Strand Mat Method, USU Physics, 2-3. 2013.

[4] Fauzi, The Effect of Alkali Treatment, Fiber Volume and Fiber Length Contraction on The Tensile Strength of Polyester Coconut Fiber Composite Fibers, Journal of Materials and Manufacturing Process, 31-34. 2017.

[5] Rafael, EU, 2015. The Effect of The Treatment of Coconut Fiber Alkali on Tensile Strength, Lontar Journal of Undana Mechanical Engineering, 1-4. 2017.

[6] Mulinari, D.R.; Baptista, C.A.R.P.; Souza, J. V. C.; Voorwald, H.J.C., Mechanical Properties of Coconut Fibers Reinforced Polyester Composites, Procedia Engineering 10, 2074-2079. 2011

[7] Jonathan, I.F, Analysis of The Mechanical Properties of Composite Materials, Axis of Mechanical Engineering, 1-10. 2013.

[8] Diharjo, K. Effect of Alkali Treatment on The Tensile Properties of Composite Materials of Hemp FiberPolyester, Jurnal Teknik Mesin, Vol. 8, No. 1, 8-13. 2006.

[9] Sudrajat, B.A., Effect of Weight Percentage of Coconut Fiber and Corn Husk on The Flexural Strength of Hanging Racks, Study Final Report, Diploma IV in Production and Maintenance Engineering, Department of Mechanical Engineering, State Polytechnic of Malang, Malang. 2019.

[10] Anonymous, Standard Test Method for Flexural Properties of Polymer Matrix Composite Materials, ASTM-D7264, ASTM International. 2008.

[11] Hadi, Syamsul, Material Technology, Andi Offset, Yogyakarta. 2016.

[12] Callister, W.D., Materials Science and Engineering: An Introduction. Wiley Asia Student Edition, John Wiley and Sons, Inc., 7th Edition, Salt Lake City, Utah, USA. 2007.

[13] Anonymous, The Percentage Point Distribution F Probability 0.05,http://ledhyane.lecture.ub.ac.id/files/2013/07/tabelf-0-05.pdf, accessed August 22, 2019.

[14] Obele, Chizoba; Ishidi, E., Mechanical Properties of Coir Fiber Reinforced Epoxy Resin Composites for Helmet Shell, Industrial Engineering Letters, www.iiste.org Vol.5, No.7, 67-74. 2015.

[15] Jagadeesh, D.; Sudhakara, P.; Lee, D.W.; Kim, H.S.; Kim, B.S.; Song, J.I., Mechanical Properties of Corn Husk Flour/PP Bio-Composites, Composites Research, Vol. 26, No. 4, 213-217. 2013. 